\title{
Novas espécies de Cerambycidae (Coleoptera) neotropicais
}

\author{
Ubirajara R. Martins ${ }^{1}$ \\ Maria Helena M. Galileo ${ }^{2}$
}

\begin{abstract}
New species of Neotropical Cerambycidae (Coleoptera). The following new species are described: Eburiini-Eburella longicollis (Bolívia, Província del Sara), Cupanoscelis serrana (Brazil, Goiás); Onciderini - Sternycha panamensis (Panamá, Panamá), Cacostola nordestina (Brazil, Paraíba); Apomecynini-Parmenonta chapadensis (Brazil, Mato Grosso), P. maculata (Argentina, Salta); Phacellini Piola rubra (Bolívia, Santa Cruz), P. unicolor (Brazil, Pará), P. colombica (Colombia, Bolivar); Desmiphorini - Maltonea itaiuba (Venezuela, Mérida). Notes on Piola quiabentiae Marinoni, 1974 and keys to the South American species of Parmenonta Thomson, 1868 and Piola Marinoni, 1974 are added.

KEY WORDS. Coleoptera, Cerambycidae, Lamiinae, neotropical, taxonomy
\end{abstract}

Nesta contribuição são descritas dez espécies de cerambicídeos neotropicais, principalmente da América do Sul. As abreviaturas citadas ao longo do texto são: (CMNC) Canadian Museum of Nature, Ottawa; (CMNH) Carnegie Museum of Natural History, Pittsburgh; (IAHC) Instituto de Investigación de Recursos Biológicos Alexander von Humboldt, Villa de Leyva; (MCNZ) Museu de Ciências Naturais, Porto Alegre; (MZSP) Museu de Zoologia, Universidade de São Paulo, São Paulo.

\section{Cerambycinae \\ Eburiini}

\section{Eburella longicollis sp.n.}

Fig. 1

Macho. Cabeça com tegumento vermelho-alaranjado, brilhante. Pontuação rasa e moderadamente densa na fronte. Vértice com alguns pontos rasos. Lobos superiores dos olhos com cinco fileiras de omatídios; tão distantes entre si quanto o dobro da largura de um lobo. Antenas vermelho-alaranjadas com uma vez e meia o comprimento do corpo. Escapo cilíndrico, levemente curvo, sem sulco no lado superior da base. Antenômero III desprovido de sulco ou carena, tão longo quanto 1,2 vezes o IV. Protórax vermelho-alaranjado, mais longo do que largo; espinhos laterais diminutos, situados ao nível do terço basal. Pronoto regularmente convexo sem tubérculos ou depressões; superfície microesculturada (50x). Partes laterais do

1) Museu de Zoologia, Universidade de São Paulo. Caixa Postal 42694, 4299-970 São Paulo, São Paulo, Brasil. Pesquisador CNPq.

2) Museu de Ciências Naturais, Fundação Zoobotânica do Rio Grande do Sul. Caixa Postal 1188, 90001-970 Porto Alegre, Rio Grande do Sul, Brasil. Pesquisador CNPq. 
protórax com pontuação sexual no meio que se prolonga, indistintamente, pela metade posterior do prosterno. Metasterno com pontos evidentes, esparsos. Élitros alaranjados, mais claros para a metade apical; densamente pontuados em toda a superfície; cada um com três manchas ebúrneas bem elevadas: uma basal, elíptica e duas centrais, contíguas, alongadas, a externa ultrapassa posteriormente a interna em pequena extensão; região posterior da mancha ebúrnea basal e regiões anterior e posterior das manchas centrais com tegumento enegrecido. Extremidades elitrais emarginadas com espinho concolor no lado externo e ligeiramente projetadas no ângulo sutural. Fêmures amarelados, enegrecidos no ápice; meso- e metafêmures com espinho no lado interno. Metafêmures atingem a ponta dos élitros. Tíbias e tarsos amarelados; tarsômeros não intumesidos. Urosternitos sem áreas pilosas.

Dimensões. Comprimento total 5,9 mm; comprimento do protórax 1,1 mm; maior largura do protórax $0,9 \mathrm{~mm}$; comprimento do élitro $4,2 \mathrm{~mm}$; largura umeral $1,2 \mathrm{~mm}$.

Material-tipo. Holótipo macho, BolíviA, Provincia del Sara: Steinbach leg., C.M. Acc. 5043 (CMNH).

Discussão. O gênero Eburella foi estabelecido por MONNÉ \& MARTINS (1973) para E. pumicosa, procedente do Brasil, Mato Grosso do Sul, Salobra. MARTINS (1997) acrescentou, ao gênero, E. pinima da Bolívia.

Eburella longicollis difere de E. pumicosa pelo protórax mais longo do que largo; pelos tarsômeros não-engrossados; pela ausência de áreas pubescentes no abdômen dos machos e pelas partes laterais de protórax com pontuação sexual. Distingue-se de E. pinima, que também ocorre na Bolívia, pela presença de espículos nos lados do protórax; pelas manchas ebúrneas centrais a externa pouco mais longa que a interna; pelo tegumento preto na parte posterior e anterior das machas ebúrneas e pelas extremidades dos fêmures escurecidas. Além disso, diferem pela relação comprimento do élitro/largura umeral que em Eburella pinima é igual a 4,1 e em $E$. longicollis, 3,5.

\section{Cupanoscelis serrana sp.n.}

Fig. 2

Macho. Tegumento laranja-avermelhado, densamente pontuado. Fronte transversal; a largura igual ao dobro do comprimento. Vértice densamente pontuado. Tubérculos anteníferos pouco projetados. Lobos oculares superiores com quatro fileiras de omatídios, tão distantes entre si quanto o dobro da largura de um lobo. Lobos oculares inferiores desenvolvidos, ocupam todo lado da cabeça. Antenas com onze artículos, atingem o ápice elitral na extremidade do antenômero VIII. Escapo fortemente curvo; região basal deprimida e densamente pontuada, restante da superfície lisa e brilhante. Antenômeros basais sulcados e carenados com longos pêlos no lado interno; o III mais longo do que o IV. Protórax tão largo quanto longo. Espinho lateral discreto, situado ao nível do meio; pronoto sem tubérculos, com pontos grossos e densos em toda superfície. Pro- e mesosterno densamente pontuados. Metasterno com pontos esparsos. Cada élitro com três manchas ebúrneas alongadas, circundadas por tegumento preto: uma na base e duas centrais desiguais, 
separadas por área equivalente à largura de uma mancha; a interna mais curta, situada à frente da externa, termina posteriormente ao nível do meio da externa; ápices dos élitros obliquamente truncados; superfície densamente pontuada, com pêlos muito longos. Base das epipleuras sem espículo. Fêmures amarelo-alaranjados com extremidades concolores. Meso- e metafêmures com espinho no lado interno do ápice. Metatíbias visivelmente espessadas na metade apical. Tarsômeros engrossados.
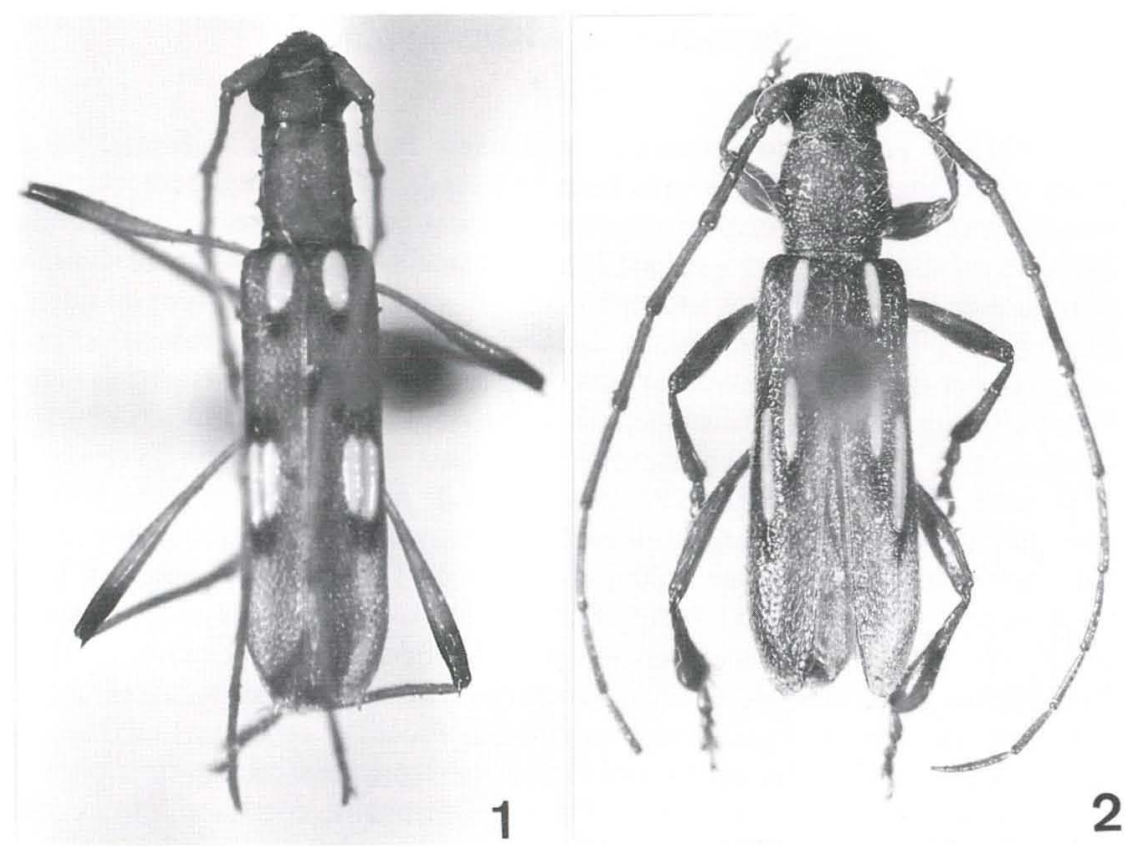

Figs 1-2. (1) Eburella longicollis sp.n., holótipo macho, comprimento 5,9 mm; (2) Cupanoscelis serrana sp.n., holótipo macho, comprimento $6,2 \mathrm{~mm}$.

Dimensões. Comprimento total 6,2 $\mathrm{mm}$; comprimento do protórax 1,2 $\mathrm{mm}$; maior largura do protórax 1,2 $\mathrm{mm}$; comprimento do élitro $4,5 \mathrm{~mm}$; largura umeral $1,5 \mathrm{~mm}$.

Material tipo. Holótipo macho, BRAsIL, Goiás: Minaçu (Serra da Mesa), 19-30.XI.1996, L. Moura leg. (MCNZ).

Discussão. Pela chave para determinação das espécies do gênero Cupanoscelis publicada por MONNÉ \& MARTINS (1992), Cupanoscelis serrana corresponde ao dilema 4 , isto é, élitros com faixas ebúrneas alongadas, separadas entre si por distância correspondente à largura de uma faixa. Neste dilema separam-se duas espécies, C. inermis Monné \& Martins, 1992 e C. latitibialis Monné \& Martins, 1992. Cupanoscelis serrana distingue-se de C. latitibialis pelo protórax sem tubérculo lateral evidente; pelo pronoto densa e uniformemente pontuado e pelas extremidades elitrais desarmadas. Difere de C. inermis pelo número e comprimento das 
faixas ebúrneas dos élitros, que nesta espécie são apenas duas, muito longas (a basal ultrapassa o meio e a central, inicia-se ao nível da interna e estende-se até o terço apical) e pelas metatíbias engrossadas. Em $C$. inermis esse espessamento é apenas no terço apical e em C. serrana ocupa toda a metade apical.

\section{Lamiinae}

\section{Onciderini}

\section{Sternycha panamensis sp.n.}

Fig. 3

Macho. Tegumento vermelho-acastanhado. Pubescência uniforme, fulva. Fronte mais longa $(1,6 \mathrm{~mm})$ do que larga $(1,3 \mathrm{~mm})$; sutura frontal bem marcada, continuada pela sutura coronal até o occipício. Lobos oculares superiores com cinco fileiras de omatídios (largura igual a $0,2 \mathrm{~mm}$ ); distância entre os lobos igual ao triplo da largura de um lobo. Lobos inferiores dos olhos mais longos $(7 \mathrm{~mm})$ do que as genas $(5 \mathrm{~mm})$. Tubérculos anteníferos agudos, distantes entre si. Antenas alcançam o ápice dos élitros e estão revestidas por pubescência fulva; base dos antenômeros $\mathrm{V}$ a XI com pubescência indistintamente mais clara. Escapo subcilíndrico, comprimento $1,1 \mathrm{~mm}$, muito ligeiramente engrossado para o ápice, com franja densa de pêlos curtos. Antenômero III com leve sinuosidade na base, provido de franja de pêlos curtos e densos na margem interna; comprimento 2,2 $\mathrm{mm}$. Antenômero IV reto, com menos pêlos do que no III; comprimento 1,5 mm. Antenômero V com franja esparsa; comprimento $1,0 \mathrm{~mm}$. Protórax tronco-cônico, mais estreito na orla anterior $(2,3 \mathrm{~mm})$ do que na posterior $(2,8 \mathrm{~mm})$. Lados do protórax com sulco ao nível do terço basal, prolongado obliquamente para o dorso. Pronoto sem elevações, com uma área central ligeiramente deprimida. Processo prosternal com nítida elevação transversal no meio. Processo mesosternal com tubérculo muito projetado e voltado para o processo prosternal. Élitros regularmente convexos, as margens levemente estreitadas para o ápice. Úmeros pouco projetados, sem vestígio de carena. Ápices arredondados em conjunto. Pontuação gradualmente menos profunda para a extremidade; na base acobertada pela pubescência. Profêmures fusiformes; comprimento 2,0 mm. Meso-e metafêmures com comprimento subigual $(2,2 \mathrm{~mm})$. Tíbias tão longas quanto os respectivos fềmures; as posteriores não-engrossadas. Metatarsômeros I-III subiguais ao dobro do comprimento do V. Urosternitos com faixa central desnuda e brilhante. Urosternito $\mathrm{V}$ sem pubescência mais clara, com a borda apical levemente emarginada.

Dimensões. Comprimento total 10,3 mm; comprimento do protórax 1,8 mm; maior largura do protórax no meio $2,6 \mathrm{~mm}$; comprimento do élitro $7,5 \mathrm{~mm}$; largura umeral $3,7 \mathrm{~mm}$.

Material-tipo. Holótipo macho, PANAMÁ, Panamá: Cerro Campana (500 m), 5.I.1981, G. Ekis leg. (CMNH).

Discussão. O gênero Sternycha Dillon \& Dillon, 1945 tem cinco espécies conhecidas: S. paupera (Bates, 1885), S. sternalis Dillon \& Dillon, 1945, S. approximata Dillon \& Dillon, 1945, S. clivosa Martins \& Galileo, 1990 e S. diasi Martins \& Galileo, 1990 

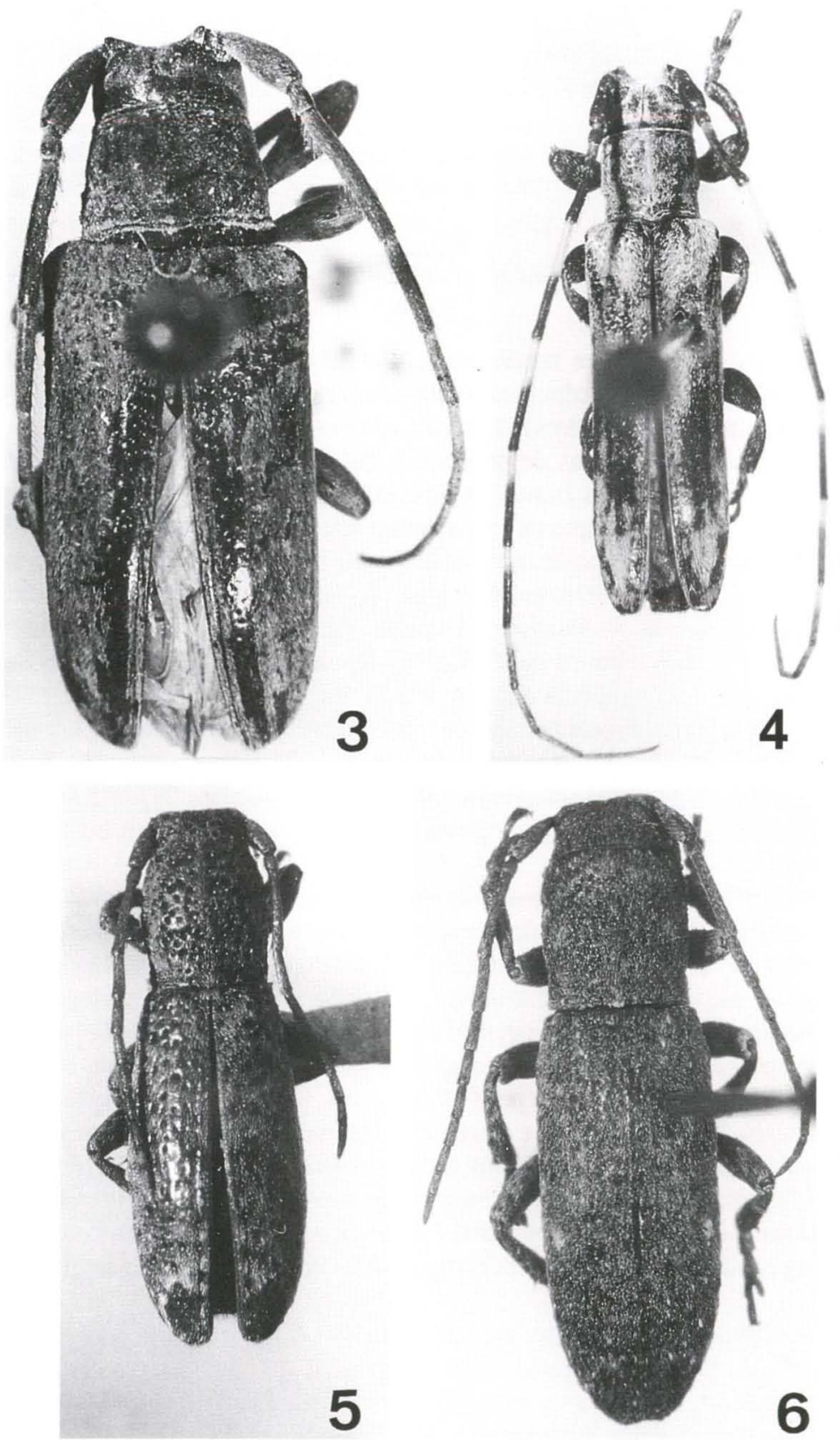

Figs 3-6. (3) Sternycha panamensis sp.n., holótipo macho, comprimento 10,3; (4) Cacostola nordestina sp.n., holótipo macho, comprimento $7,5 \mathrm{~mm}$; (5) Parmenonta chapadensis sp.n., holótipo fêmea, comprimento 6,9 ; (6) P. maculata sp.n., holótipo fêmea, comprimento 10,2 $\mathrm{mm}$. 
Sternycha sternalis, conhecida do Brasil, Pará (DiLlon \& Dillon 1945), e S. clivosa, descrita da Bolívia (MARTINS \& GALILEO 1990), apresentam elevação transversal no processo prosternal como em S. panamensis. Sternycha panamensis distingue-se de S. sternalis e de S. clivosa: pela pubescência corporal uniforme, sem estar entremeada por pubescência castanho-escura e sem mácula de pubescência branca no dorso dos élitros; e, também, pela faixa glabra no centro dos urosternitos.

\section{Cacostola nordestina sp.n.}

Fig. 4

Macho. Cabeça com tegumento castanho-escuro; pubescência amarelada com duas máculas de pubescência castanho-escura na parte inferior da fronte. Fronte tão larga quanto longa. Tubérculos anteníferos projetados, agudos. Lobos oculares superiores com cinco fileiras de omatídios, tão distantes entre si quanto quase o dobro da largura de um lobo. Lobos oculares inferiores com o dobro do comprimento das genas. As antenas ultrapassam as extremidades elitrais a partir da extremidade do antenômero VII. Antenômero III curvo, com 0,7 vezes o comprimento do IV. Antenômeros V-X com comprimentos gradualmente decrescentes. Antenômero XI mais longo do que o X. Escapo e pedicelo castanho-escuros. Antenômero III castanho-escuro com estreito anel basal de tegumento amarelado. Antenômeros IV-IX castanhos com a metade ou o terço basal brancos. Antenômeros X e XI com tegumento amarelado. Protórax com tegumento castanho-escuro, apenas mais largo do que longo; lados com pequena projeção situada atrás do meio. Pronoto levemente convexo com duas gibosidades apenas visíveis e região deprimida junto à orla basal; pubescência amarelada uniforme e pouco densa; de cada lado da base do pronoto uma faixa castanha.

Élitros com tegumento bicolor, amarelado com manchas e áreas castanhoescuras: uma área circum-escutelar; uma faixa irregular, oblíqua que vai dos úmeros até a sutura no terço basal; uma grande mancha com bordas irregulares, atrás do meio, que se estende quase até à sutura; pequenas manchas irregulares no quinto apical; úmeros sem carena; extremidades arredondadas. Pontuação dos élitros grossa e esparsa, no dorso, até pouco além do meio e, junto à margem, até o ápice. Fêmures castanho-escuros, com pedúnculo curto e fortemente engrossado nos dois terços apicais. Tíbias castanho-escuras, espessadas. Tarsômero V com tegumento pouco mais claro. Esternos torácicos com pubescência amarelada uniformemente distribuída; urosternitos com pêlos concentrados em manchas irregulares.

Dimensões. Comprimento total 7,5 mm; comprimento do protórax $1,3 \mathrm{~mm}$; maior largura do protórax 1,4 mm; comprimento do élitro 5,4 mm; largura umeral $1,9 \mathrm{~mm}$.

Material-tipo. Holótipo macho, Brasil, Paraíba: São José da Mata, 10.IV.1997, A. Brescovit leg. (MZSP).

Discussão. A espécie que mais se assemelha a Cacostola nordestina pelo padrão de colorido geral e das antenas é C. vanini Martins, 1979 procedente de Minas Gerais, Brasil. Em C. vanini, além de detalhes na distribuição do padrão de colorido, a pubescência elitral tem três colorações: amarelada, esbranquiçada e acastanhada e as dimensões são bem maiores, comprimento $11,5 \mathrm{~mm}$ e largura umeral $2,7 \mathrm{~mm}$. 


\section{Apomecynini}

\section{Parmenonta Thomson, 1868}

Parmenonta Thomson, 1868: 157. - Monné, 1994a: 32 (cat.).

Segundo Monné (1994a), este gênero contém doze espécies, das quais, quatro ocorrem na América do Sul: $P$. paralella Lameere (Venezuela), $P$. albisetosa Bates (Guatemala à Venezuela), P. punctigera (Germar) (Brasil: Minas Gerais à Santa Catarina) e $P$. strandiella Breuning (Paraguai e Argentina).

BREUNING (1971: 318) apresentou uma chave para a identificação das espécies e as que têm registro para a América de Sul, foram assim separadas: discriminou $P$. punctigera pela presença de mancha escura na extremidade dos élitros. Distinguiu $P$. strandiella de $P$. albisetosa e de $P$. parallela pelo antenômero IV subigual em comprimento ao $\mathrm{V}$ e pelos élitros não-salpicados de pequenas manchas esbraquiçadas.

A estas adicionam-se agora duas novas espécies sul-americanas, Parmenonta chapadensis e $P$. maculata.

\section{Chave para as espécies sul-americanas de Parmenonta}

1. Élitros com uma mancha apical castanho-escura, bordejada anteriormente por pubescência esbranquiçada . . . . . . . . . . . . . . 2

- Élitros sem mancha apical castanho-escura . . . . . . . . . . . . . . 3

2(1). Élitros com pequena mancha de pubescência branca no dorso atrás do meio; pubescência amarelada concentrada numa faixa estreita, nítida, na borda anterior da mancha castanha apical. Brasil (Minas Gerais a Santa Catarina)

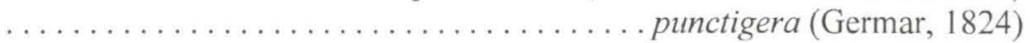

- Élitros sem mancha de pubescência branca no dorso; pubescência amarelada esparsa, não constitui faixa nítida junto à mancha acastanhada apical dos élitros. Brasil (Mato Grosso) . . . . . . . . . . . . . . chapadensis sp.n.

3(1). Antenômero IV apenas mais longo do que o $\mathrm{V}$; élitros com pubescência amarelo-acastanhada uniforme. Paraguai e Argentina (Santiago del Estero). . . . . . . . . . . . . . . . . . . strandiella Breuning, 1940

- Antenômero IV mais longo do que o $\mathrm{V}$; élitros com pequenos pincéis de pêlos brancos entremeados à pubescência amarelada . . . . . . . . . . 4

4(3). Quarto apical dos élitros com uma série de máculas numa linha longitudinal descendente da sutura em direção a borda marginal apical de cílios brancos 5

- Quarto apical dos élitros sem linhas longitudinais de pubescência branca. Argentina $($ Salta $\ldots \ldots \ldots \ldots \ldots \ldots \ldots \ldots \ldots \ldots \ldots \ldots \ldots \ldots \ldots \ldots \ldots$ macula sp.n.

5(4). Pronoto densamente pontuado (BREUNING 1971: 318). Guatemala, Panamá e

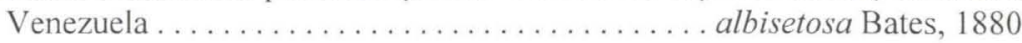

- Pronoto esparsamente pontuado (BrEUNING 1971: 318). Venezuela . . . . . . . . . parallela Lameere, 1893 


\section{Parmenonta chapadensis sp.n.}

Fig. 5

Tegumento de maneira geral avermelhado, revestido por pubescência amarelada, moderadamente densa. Cabeça grosseiramente pontuada. Olhos divididos; lobos inferiores com um terço do comprimento das genas. Antenas apenas ultrapassam o meio dos élitros. Antenômero IV com 1,4 vezes o comprimento do V. Pronoto grosseiramente pontuado; pubescência uniforme. Partes laterais do protórax pontuadas. Mesosterno com declive abrupto para o lado do processo prosternal. Mesepisternos ligeiramente pontuados. Metasterno tão longo quanto o urosternito I, com pontos grossos nos lados. Élitros sem manchas dorsais de pubescência branca; extremidades ocupadas por mancha castanha, estreita, bordejada anteriormente por pubescência clara e irregular, que não constitui uma faixa nítida.

Dimensões. Comprimento total 6,6-8,9 mm; comprimento do protórax 1,82,5 mm; maior largura do protórax 1,7-2,2 mm; comprimento do élitro 4,4-5,8 mm; largura umeral 1,7-2,3 mm.

Material-tipo. Holótipo fêmea, Brasil, Mato Grosso: Chapada [dos Guimarães], Novembro, Acc. 2966 (CMNH). Parátipos, 2 fêmeas, mesmos dados do holótipo, abril (MZSP); outubro (CMNH).

Discussão. Nesta espécie a ponta dos élitros está ocupada por mancha escura como em Parmenonta punctigera, entretanto, essa mancha é mais estreita e a bordadura de pubescência esbranquiçada é mais larga e pouco regular. Além disso, $P$. chapadensis não tem a pequena mancha dorsal de pubescência esbranquiçada próxima do meio dos élitros.

\section{Parmenonta maculata sp.n.}

Fig. 6

Tegumento castanho-avermelhado, revestido por pubescência grosseira amarelada. Fronte grosseiramente pontuada. Olhos divididos; lobos inferiores com um terço do comprimento das genas. Antenas apenas ultrapassam o meio dos élitros. Antenômero IV com 1,4 do comprimento do antenômero V. Pronoto com pubescência densa, amarelada e um pequeno tufo branco à frente do escutelo. Disco pronotal com pontos grossos. Élitros uniformemente revestidos por pubescência grosseira amarelada, entremeada por pequenos pincéis de pubescência branca; uma mancha de pubescência branca, dorsal, pouco atrás do meio; superfície grosseiramente pontuada. Mesosterno com declive pouco acentuado para o lado do prosterno. Mesepisternos grosseiramente pontuados. Metasterno e urosternitos pontuados.

Dimensões. Comprimento total 10,2 $\mathrm{mm}$; comprimento do protórax 2,5 mm; maior largura do protórax $2,5 \mathrm{~mm}$; comprimento do élitro $6,9 \mathrm{~mm}$; largura umeral $2,7 \mathrm{~mm}$.

Material-tipo. Holótipo fêmea, ArgentinA, Salta: San Lorenzo, I.1949, A. Martinez leg. (MZSP).

Discussão. Esta espécie possui uma pubescência corporal relativamente grosseira e não apresenta mancha acastanhada na extremidade dos élitros. Parme- 
nonta maculata difere de $P$. strandiella, além da pilosidade grosseira, pela desuniformidade da pilosidade elitral, neste caso com pincéis brancos e esparsos; pela mancha de pubescência esbranquiçada, evidente, dorsal, situada logo atrás do meio.

Distingue-se de $P$. albisetosa e de $P$. parallela, espécies ocorrentes no norte da América do Sul, pela ausência de manchas de pubescência esbranquiçada organizadas em faixa oblíqua e em sentido descendente da sutura para a margem, na metade apical.

\section{Phacellini}

\section{Piola Marinoni, 1974}

Piola Marinoni, 1974: 86. - Monné, 1994b: 86 (cat.).

O gênero Piola, monotípico, foi proposto por MARINONI (1974) para $P$. quiabentiae procedente da Argentina: Salta e do Brasil: Mato Grosso. O material argentino foi coletado sobre Quiabentia pflanzii (Vaup.) (Cactaceae). Constatamos mais três espécies desse gênero e as quatro espécies que o constituem distinguem-se como segue.

\section{Chave para as espécies de Piola}

1. Quarto basal dos élitros glabro com tegumento uniformemente avermelhado; escutelo glabro (Fig. 7). Bolívia ................... rubra sp.n. -Élitros inteiramente cobertos por pubescência; escutelo com pubescência. . . . 2 2(1). Pubescência elitral variegada de mais de uma cor; setas acastanhadas, longas e densas . . . . . . . . . . . . . . . . . . . . . . . . . . 3

-Élitros com pubescência esbranquiçada, uniforme; setas brancas, curtas e esparsas (Fig. 8). Brasil (Pará) . . . . . . . . . . . . . . . . . unicolor sp.n.

3(2). Flagelômeros com o ápice acastanhado; distância entre os lobos oculares superiores (fêmea) subigual à largura de um lobo (Fig. 9). Colômbia . . . . . colombica sp.n.

- Flagelômeros unicolores; distância entre os lobos oculares superiores (fêmea) quase igual ao dobro da largura de um lobo. Brasil (Mato Grosso, Mato Grosso do Sul, São Paulo), Argentina (Salta) . . quiabentiae Marinoni, 1974

\section{Piola rubra sp.n.}

Fig. 7

Fêmea. Tegumento avermelhado. Fronte transversal, revestida por densa pubescência branco-amarelada e pêlos abundantes acastanhados. Olhos bem desenvolvidos; lobos superiores com oito fileiras de omatídios, tão distantes entre si quanto a largura de um lobo; lobos inferiores ocupam quase todo lado da cabeça. Genas muito curtas. Antenas alcançam as pontas dos élitros na extremidade do antenômero IX. Escapo castanho-avermelhado. Demais antenômeros avermelhados com anel basal pouco contrastante de pilosidade esbranquiçada. Protórax averme- 

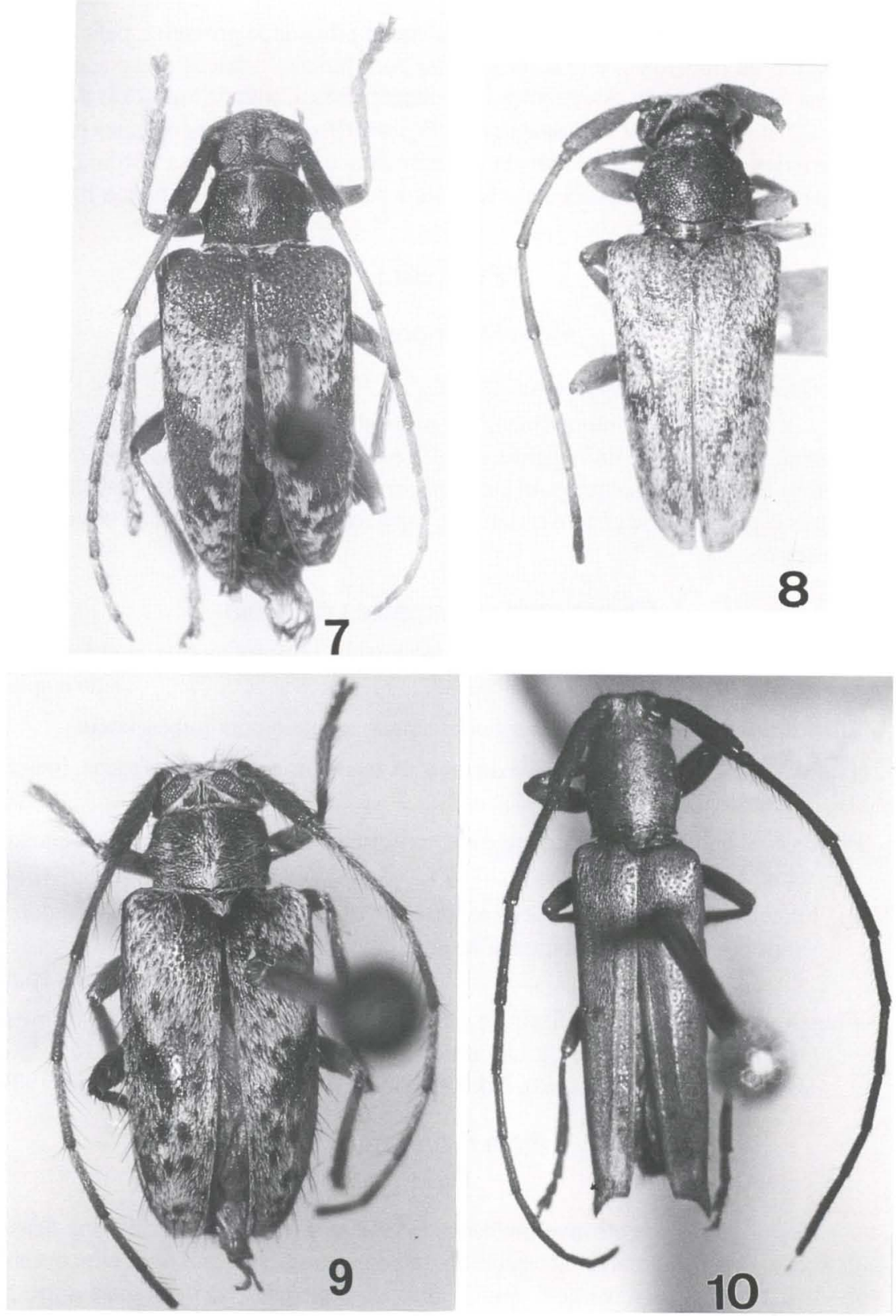

Figs 7-10. (7) Piola rubra sp.n., holótipo fêmea, comprimento 8,7 mm; (8) P. unicolor sp.n., holótipo macho, comprimento $6,1 \mathrm{~mm}$; (9) $P$. colombica sp.n., holótipo fêmea, comprimento 5,0; (10) Malthonea itaiuba sp.n., holótipo macho, comprimento $7,7 \mathrm{~mm}$. 
Ihado, com pouca pubescência; centro do pronoto com área longitudinal coberta por pubescência densa amarelo-esbranquiçada. Disco com grande gibosidade central, fina e densamente pontuado em toda superfície; sulcos anterior e basal não aparentes. Pêlos escuros abundantes em toda superfície. Partes laterais do protórax com espinho central desenvolvido e curvo; a ponta voltada para trás. Escutelo avermeIhado, glabro. Élitros com tegumento avermelhado; quinto basal praticamente glabro, delimitado posteriormente por uma área triangular de pubescência esbranquiçada, densa; esta área na região sutural, estende-se até além do meio e continua, junto da sutura, até o terço apical onde é mais larga e está entemeada por áreas pequenas e glabras. Essa pubescência esbranquiçada delimita, para o lado da margem, uma grande área avermelhada. Élitros providos de abundantes setas acastanhadas. Pontuação elitral muito densa e muito próxima na região glabra basal. Pernas avermelhadas revestidas por pubescência esbranquiçada. Face ventral do corpo avermelhada com densa pubescência esbranquiçada.

Dimensões. Comprimento total 7,5-8,7 mm; comprimento do protórax 1,31,4 mm; maior largura do protórax 2,2-2,4 mm; comprimento do élitro 5,3-6,3 mm; largura umeral 3,0-3,5 mm.

Material-tipo. Holótipo fêmea, Bolivia, Santa Cruz: Santa Cruz (600 m), 24.X.1969, Zischka leg. (MZSP); parátipo fêmea, Bolivia, Santa Cruz: Buena Vista, X.1949, Prosen leg. (MZSP).

Discussão. Piola rubra distingue-se de $P$. quiabentiae principalmente pelo escutelo glabro; pelos élitros avermelhados e glabros no quinto anterior e nos lados para atrás do meio. Em $P$. quiabentiae o escutelo é densamente revestido por pubescência amarelada e os élitros são inteiramente pubescentes com padrão colorido diferente.

\section{Piola unicolor sp.n.}

Fig. 8

Macho. Caracteres morfológicos como em P. rubra exceto: tegumento avermelhado; lobos superiores dos olhos com seis fileiras de omatídios, separados entre si por distância equivalente a quase o dobro da largura de um lobo; antenas vermelho-alaranjadas, atingem as pontas dos élitros na extremidade do antenômero VIII; protórax com pubescência rala, unicolor, esbranquiçada; gibosidade pronotal regularmente convexa, menos projetada; escutelo revestido por pubescência esbranquiçada; pubescência elitral uniforme, esbranquiçada entemeada por setas amareladas; pernas com tegumento vermelho-alaranjado.

Dimensões. Comprimento total $6,1 \mathrm{~mm}$; comprimento do protórax $1,2 \mathrm{~mm}$; maior largura do protórax $1,8 \mathrm{~mm}$; comprimento do élitro $4,3 \mathrm{~mm}$; largura umeral $2,3 \mathrm{~mm}$. (CMNH).

Material-tipo. Holótipo macho, Brasil, Pará: Santarém, Acc. 2966

Discussão. Piola unicolor caracteriza-se pela pubescência esbranquiçada, uniforme, em toda face dorsal do corpo. 
Nos dois sexos de $P$. quiabentiae os lobos superiores dos olhos têm sete fileiras de omatídios e, nos machos de $P$. unicolor (único sexo conhecido) têm apenas seis fileiras de omatídios. Machos de $P$. rubra e $P$. colombica são desconhecidos, portanto, até o momento, o número de fileiras de omatídios serve apenas para distinguir $P$. unicolor de $P$. quiabentiae.

\section{Piola colombica sp.n.}

Fig. 9

Tegumento de maneira geral acastanhado. Fronte revestida por pubescência esbranquiçada, densa e longa. Lobos oculares superiores com 6-7 fileiras de omatídios; distância entre lobos subigual à largura de um lobo. Escapo acastanhado. Flagelômeros com as metade basal esbranquiçada e a metade apical acastanhada. Protórax com tegumento acastanhado, revestido por pubescência esbranquiçada; centro do pronoto com área, mais ou menos losangular, revestida por densa pilosidade esbranquiçada. Espinho lateral do protórax bem desenvolvido, com ápice voltado para trás. Escutelo revestido por pilosidade amarelada ou esbranquiçada. Élitros com tegumento castanho, recobertos principalmente por pilosidade esbranquiçada e muitas setas escuras, longas; área circum-escutelar acastanhada; uma grande área central, junto à margem lateral, de pubescência amarelada e uma área acastanhada fundida a ela no lado ântero-interno; metade apical com máculas esparsas de pubescência castanha. Friso sutural revestido por pubescência amarelada. Face ventral recoberta por pubescência branco-amarelada.

Dimensões. Comprimento total 5,9-7,1 mm; comprimento do protórax 1,01,3 mm; maior largura do protórax 1,8-2,5 mm; comprimento do élitro 4,3-5,2 mm; largura umeral 2,3-3,0 $\mathrm{mm}$.

Material-tipo. Holótipo fêmea, ColôMBIA, Bolivar: Zambrano (Hacienda Monterrey, 9³7’48"N 7454’44"W, 70 m), 30.III.1994, F. Fernández \& G. Ulloa leg. (Malaise, "bosque de Chile") (MZSP); parátipos, 2 fêmeas, mesmos dados do holótipo, 14.IV.1994 (IAHC).

Discussão. Piola colombica caracteriza-se pelos flagelômeros bicolores; pelos lobos superiores dos olhos mais próximos entre si; pela pubescência esbranquiçada densa na fronte e no centro do disco pronotal e pela presença de manchas de pubescência acastanhada nos élitros.

\section{Piola quiabentiae Marinoni, 1974}

Piola quiabentiae Marinoni, 1974: 88, figs 1-9. - Monné, 1994b: 26 (cat.).

Além de um parátipo fêmea de Salta, Argentina examinamos o seguinte material: BRASIL, Mato Grosso do Sul: Salobra (Zona da estrada de ferro ao noroeste do Brasil), macho, fêmea, 18-29.X.1978 (MZSP); São Paulo: Ibirá, fêmea, X.1953 (MZSP).

Discussão. Piola quiabentiae difere de $P$. colombica principalmente pelos flagelômeros unicolores e pela distribuição da pubescência esbranquiçada nos élitros. 


\section{Desmiphorini}

\section{Malthonea itaiuba sp.n.}

Fig. 10

Etimologia. Tupi: itaíuba = ouro, alusivo a pubescência corporal amarelodourada.

Macho. Tegumento vermelho-acastanhado. Antenas e pernas com tegumento castanho-avermelhado. Todo o corpo revestido por pubescência amarelo-dourada, densa. Tubérculos anteníferos projetados. Lobos superiores dos olhos estreitos, com quatro fileiras de omatídos; tão distantes entre si quanto o quíntuplo da largura de um lobo. Lobos oculares inferiores $(0,4 \mathrm{~mm})$ apenas mais curtos do que as genas $(0,5 \mathrm{~mm})$. Antenas ultrapassam o ápice elitral, aproximadamente, a partir do ápice do antenômero VI. Protórax pouco mais largo anteriormente $(1,3 \mathrm{~mm})$ do que na base $(1,2 \mathrm{~mm})$. Espinhos laterais do protórax diminutos, situados ao nível do meio. Pubescência pronotal convergente para o centro. Élitros com carena elevada, paralela à sutura, nos três quartos apicais; pubescência elitral densa, com raras (3 ou 4) máculas mais escuras no terço apical, entre a carena e a sutura; extremidades cortadas em curva com espinho levemente divergente, longo (mais longo do que o pedicelo) no lado externo. Protarsos ligeiramente intumescidos. Processo mesosternal sem tubérculo. Lados do metasterno e do urosternito I, fina e esparsamente pontuados.

Dimensões. Comprimento total 7,7 mm; comprimento do protórax 1,4 mm; maior largura do protórax $1,5 \mathrm{~mm}$; comprimento do élitro $5,6 \mathrm{~mm}$; largura umeral $1,9 \mathrm{~mm}$.

Material-tipo. Holótipo macho, Venezuela, Mérida: El Valle $(15 \mathrm{~km} \mathrm{NE}$ de Mérida; 2400 m; "cloud forest"), 24.VI-2.VII.1989, S. \& J. Peck leg. (CMNC).

Discussão. Segundo a chave para espécies do gênero Malthonea (MARTINS \& GALILEO 1995, modificada por GALILEO \& MARTINS 1996), M. itaiuba assemelha-se, pelo processo mesosternal sem tubérculo e pelos élitros com pubescência uniforme amarelo-dourada, a M. aurescens (Breuning, 1966) e a M. mimula Martins \& Galileo, 1995 procedentes, respectivamente, do Equador e da Colômbia (Santander).

Malthonea itaiuba distingue-se de M. aurescens pelos lobos inferiores dos olhos pouco mais curtos que as genas, pelos lobos oculares superiores com quatro fileiras de omatídios e separados por distância aproximadamente igual ao quíntuplo da largura de um lobo; pelo tegumento das antenas e dos fêmures castanho-avermelhado contrastando com o do corpo que é mais avermelhado. Em M. aurescens os lobos oculares inferiores têm quase o dobro do comprimento das genas; os lobos oculares superiores têm cinco fileiras de omatídios e a distância entre lobos é igual ao quádruplo da largura de um lobo; o tegumento das antenas e das pernas é avermelhado como o restante do corpo.

Separa-se Malthonea itaiuba de M. mimula pelos lobos oculares superiores com quatro fileiras de omatídios, pelo espinho lateral do protórax diminuto, sensivelmente mais curto do que o pedicelo e situado perto do meio; pelas extremidades elitrais com espinho marginal longo, algo divergente para o lado externo e não 
projetadas no ângulo sutural. Em M. mimula os lobos oculares superiores têm cinco fileiras de omatídios, os espinhos laterais do protórax, tão longos quanto o pedicelo e situados aproximadamente ao nível do terço posterior; as extremidades elitrais são cortadas em curva e projetadas no ângulo sutural e, no lado externo, têm um espinho relativamente curto e não divergente.

AGRADECIMENTOS. Ao Dr. Renato C. Marinoni pelo empréstimo dos diapositivos dos tipos; a Tiago Courrol Ramos pelo auxílio na execução das fotografias. Aos Drs F. Génier (CMNC), Fernando Fernández (IAHC) e R. Davidson (CMNH) pelo envio de material para estudo.

\section{REFERÊNCIAS BIBLIOGRÁFICAS}

BREUNING, S. 1971. Révision des espèces américaines de la tribue des Apomecynini Lac. (Coleoptera, Cerambycidae). Ent. Abh. staat. Mus. Tierk., Dresden, 37 (3): 209-335.

Dillon, L.S. \& E.S. Dillon. 1945. The tribe Onciderini (Coleoptera: Cerambycidae). Reading pub. Mus. Art Gall. Sci Publ., Reading, (5): $\mathrm{XV}+1-186$.

Galileo, M.H.M. \& U.R. Martins. 1996. Notas e descrições em Desmiphorini (Coleoptera, Cerambycidae, Lamiinae), com uma revisão do gênero Mimasyngenes Breuning. Revta bras. Zool., Curitiba, 13 (4): 867-882.

MARINONI, R.C. 1974. Piola quiabentiae, gen.n., sp.n., do noroeste argentino (Coleoptera, Cerambycidae, Phacellini). Revta bras. Ent., São Paulo, 18 (3): 85-92.

MARTINS, U.R. 1997. Contribuições para uma revisão das espécies sul-americanas da tribo Eburiini (Coleoptera, Cerambycidae). Revta bras. Ent., São Paulo, 41 (1): $57-83$

Martins, U.R. \& M.H.M. GaliLeO. 1990. Onciderini (Coleoptera, Cerambycidae, Lamiinae): sinonímias, novos táxons, chaves e notas. Papéis Avuls Zool., São Paulo, 37 (4): 53-95.

- 1995. Revisão do gênero Malthonea Thomson, 1864 (Coleoptera, Cerambycidae, Lamiinae, Desmiphorini). Revta bras. Ent., São Paulo, 39 (3): 611-621.

Monné, M.A. 1994a. Catalogue of the Cerambycidae (Coleoptera) of the Westwern Hemisphere. Part XIV. São Paulo, Sociedade Brasileira de Entomologia, 72p.

1994b. Catalogue of the Cerambycidae (Coleoptera) of the Westwern

Hemisphere. Part XVI. São Paulo, Sociedade Brasileira de Entomologia, 98p.

MonNÉ, M. A. \& U.R. MARTINs. 1973. Notas e descrições em Eburiini (Coleoptera, Cerambycidae). Papéis Avuls Zool., São Paulo, 27 (11): 145-155.

- 1992. Eburiini (Coleoptera, Cerambycidae) chave para os gêneros, chave para as espécies de Cupanoscelis Gounelle, 1909, novas sinonímias e descrições de novos táxons. Revta bras. Ent., São Paulo, 36 (2): 263-275.

THOMson, J. 1868. Matériaux pour servir a une révision des lamites (Cérambycides, Coléoptères). Physis Rec. Hist. Nat., Paris, 2 (6): 101-146.

Recebido em 20.IV.1998; aceito em 18.VIII.1999 